\title{
Serum BAFF and APRIL levels in patients with IgG4-related disease and their clinical significance
}

\author{
Kazuhiro Kiyama, Daisuke Kawabata*, Yuji Hosono, Koji Kitagori, Naoichiro Yukawa, Hajime Yoshifuji, \\ Koichiro Omura, Takao Fujii and Tsuneyo Mimori
}

\begin{abstract}
Introduction: B cell-activating factor of the tumor necrosis factor family (BAFF) and a proliferation-inducing ligand (APRIL) play a crucial role in B cell development, survival, and antibody production. Here we analyzed the serum levels of BAFF and APRIL and their respective clinical associations in patients with an immunoglobulin (Ig) G4related disease (IgG4-RD).
\end{abstract}

Methods: We measured serum levels of BAFF and APRIL in patients with IgG4-RD, primary Sjögren's syndrome (pSS), and healthy individuals. Serum BAFF and APRIL levels in IgG4-RD were assessed for correlations with serological parameters, including Ig, particularly lgG4, and the number of affected organs. Serum BAFF and APRIL levels in IgG4-RD were monitored during glucocorticoid (GC) therapy.

Results: Serum BAFF and APRIL levels in patients with IgG4-RD were significantly higher $(P<0.01)$ than in healthy individuals. The BAFF levels of patients with IgG4-RD were comparable to those of patients with pSS. Although clinical parameters, such as serum IgG4 and the number of affected organs, were not correlated with the levels of BAFF, serum APRIL levels were inversely correlated with serum lgG4 levels $(r=-0.626, P<0.05)$. While serum BAFF levels decreased following GC therapy, serum APRIL levels increased during follow-up.

Conclusion: These results indicate that BAFF and APRIL might be useful markers for predicting disease activity in IgG4-RD. Further studies are needed to elucidate the role of BAFF and APRIL in the pathogenesis of IgG4-RD.

\section{Introduction}

Immunoglobulin G4-related disease (IgG4-RD) is a multi-organ disorder characterized by hyper-IgG4 $\gamma$-globulinemia, organ infiltration of IgG4-bearing plasma cells, and tissue sclerosis [1-3]. IgG4-RD has recently been recognized as a distinct clinical entity [1-4] comprising a number of disorders, such as type 1 autoimmune pancreatitis (AIP) [3,5-7], sclerosing cholangitis [8], Mikulicz's disease (MD) [1], Küttner's tumor [9], Riedel thyroiditis [10], inflammatory aneurysm [11], tubulointerstitial nephritis [12], and retroperitoneal fibrosis $[13,14]$. Because the cause of IgG4-RD is unknown, it remains unclear whether this disease should be classified as autoimmune, allergic, or hematologic.

Hypergammaglobulinemia and the existence of disease-related autoantibodies (for example, those against

\footnotetext{
* Correspondence: yakugo@gmail.com

Department of Rheumatology and Clinical Immunology, Kyoto University Graduate School of Medicine, 54 Shogoin Kawahara-cho, Sakyo-ku, Kyoto
} 606-8507, Japan lactoferrin [15], carbonic anhydrase II (CAII) [16], amylase-alpha 2A [17], pancreatic secretory trypsin inhibitor (PSTI) [18], and plasminogen-binding protein peptide [19]) support the hypothesis that autoimmunity may participate in the pathogenesis of IgG4-RD. While the mechanism by which B cells preferentially skew IgG4class switching is still not determined, recent studies with affected tissue $[20,21]$ have suggested that $\mathrm{T}$ helper 2 (Th2) phenotypes of CD4+T cells and regulatory $\mathrm{T}$ cells play a crucial role in excessive production of IgG4 and tissue fibrosis.

$B$ cell-activating factor of the tumor necrosis factor (TNF) family (BAFF, also known as B-lymphocyte stimulator (BLyS) or TNF and apoptosis leukocyteexpressed ligand-1 (TALL-1)) and its homolog, a proliferation-inducing ligand (APRIL, also known as TNFrelated death ligand 1 (TRDL-1) or TNF and apoptosis leukocyte-expressed ligand-2 (TALL-2), are members of the trimeric TNF family, and both play an essential role in the homeostasis of peripheral B cells [22]. Both

\section{() Biomed Central}


cytokines are known to be expressed by a variety of cell types, particularly the myeloid-lineage cells $[22,23]$. BAFF is synthesized as a membrane-bound or secreted protein, while APRIL exists solely in the secreted form [24]. BAFF binds to three receptors - BAFF receptor (BAFF-R), transmembrane activator and calcium-modulating cyclophilin ligand interactor (TACI), and B cell maturation antigen (BCMA) - which are expressed by $\mathrm{B}$ cells, whereas APRIL binds to TACI and BCMA [25].

BAFF and APRIL are thought to mediate the regulation of B cell maturation, survival, CD40L-independent antibody production, and isotype switching through BAFF-R and TACI $[22,23,26,27]$. Because overexpression of BAFF is known to induce $B$ cell hyperactivation and autoimmunity in mice [28], BAFF has been considered a promoting factor in the pathogenesis of several autoimmune and allergic diseases. In fact, elevated serum levels of BAFF were observed in patients with rheumatoid arthritis (RA) [29], systemic lupus erythematosus (SLE) [30], primary Sjögren's syndrome (pSS) [31,32], inflammatory myositis (IM) [33], systemic sclerosis (SSc) [34], bronchial asthma [35], and atopic dermatitis [36], and serum BAFF levels were associated with their clinical activity. In contrast, overexpression of APRIL has not been associated with autoimmunity in mice but leads to enhanced IgM production, T cell-independent type 2 humoral responses, and $\mathrm{T}$ cell proliferation [37]. On the other hand, a lack of APRIL is associated with an increased percentage of $\mathrm{CD} 44{ }^{\text {hi }}{ }^{\mathrm{C} D} 62 \mathrm{~L}^{\text {low }}$ effector memory $\mathrm{T}$ cells and impaired class switching to $\operatorname{IgA}[38,39]$. Although APRIL has been found to be elevated in patients with autoimmune diseases, including SLE [40], pSS [32], and multiple sclerosis [41], it is still under debate whether APRIL has a role in human autoimmunity, and its circulating levels do not parallel those of BAFF,

The aim of this study was to investigate the contribution of BAFF and APRIL in the pathogenesis of IgG4RD. We assessed serum levels of BAFF and APRIL by ELISA to analyze their association with clinical manifestations, serological parameters, and treatment.

\section{Materials and methods Patients}

All patients were recruited from the Department of Rheumatology and Clinical Immunology, Kyoto University Hospital, Kyoto, Japan. Patients with IgG4-RD ( $n=$ 18; 5 females, 13 males; mean age, $68.6 \pm 12.3$ years; range, 37 to 79 years) were included in the study. Patients were diagnosed on the basis of clinicopathologic findings $[3,4]$, clinical findings (diffuse/focal enlargement or mass formation, nodular/thickened lesions in one or more organs), elevated serum IgG4 (> $135 \mathrm{mg}$ / $\mathrm{dL}$ ), and histopathologic features including infiltration of lymphocytes and IgG4-positive (+) plasma cells (IgG4 +plasma cells/IgG+plasma cells $>40 \%$ and/or IgG4+ plasma cells $>10$ cells in 5 high-power fields) with typical tissue fibrosis or sclerosis. None of the patients met the criteria for sarcoidosis, Castleman's disease, Wegener granulomatosis, malignant lymphoma, or pSS. Serum samples were obtained before $(n=13)$ and after $(n=5)$ glucocorticoid (GC) treatment, and the serum from six patients before GC treatment was drawn repeatedly during GC treatment. Ten healthy individuals and thirteen individuals with pSS were enrolled and served as healthy and disease controls, respectively. All of the patients with pSS had signs and symptoms that satisfied the Japanese Ministry of Health criteria for the diagnosis of pSS. All patients and healthy volunteers provided informed consent in accordance with the Declaration of Helsinki, before providing samples. This study was approved by the Medical Ethics Committee of Kyoto University Graduate School of Medicine.

\section{Measurement of serum levels of BAFF and APRIL}

Serum levels of BAFF were determined using an enzyme-linked immunosorbent assay (ELISA) kit (R\&D Systems, Minneapolis, MN, USA), and serum levels of APRIL were determined using an ELISA kit (BioVendor Laboratory Medicine, Modrice, Czech Republic). All serum samples were stored at $-20^{\circ} \mathrm{C}$ until use.

\section{Statistical analysis}

Statistical analysis was performed with GraphPad Prism version 5.0a software (GraphPad Software, Inc., San Diego, CA, USA). Nonparametric tests were performed using the Mann-Whitney $U$ test for comparison of the two groups. Correlations were determined by Spearman's correlation. A value of $P<0.05$ was considered statistically significant. Data are shown as mean \pm standard definition (SD).

\section{Results}

Clinical, laboratory, and histological features of immunoglobulin G4-related disease (IgG4-RD)

We measured serum levels of BAFF and APRIL in 18 patients with IgG4-RD before GC therapy (cases 1 to 13) and after GC therapy (cases 14 to 18) (Table 1). The duration of GC treatment ranged from five days to thirteen years in five patients (cases 14 to 18). Twelve of eighteen (66.7\%) patients with IgG4-RD were elderly men. Serum IgG4 levels were $>135 \mathrm{mg} / \mathrm{dL}$ in all patients. Biopsy specimens from affected tissues were obtained from 15 of 18 patients, and abundant IgG4bearing plasma cell infiltration with lymphoplasmacytic infiltrates and sclerosis was observed in all patients. Three patients (cases 7, 14, and 17), who did not agree to undergo biopsy had their conditions diagnosed as 
Table 1 Clinical characteristics of patients with immunoglobulin G4-related disease (IgG4-RD).

\begin{tabular}{lllllll}
\hline Case & Age & $\begin{array}{l}\text { Serum IgG4 } \\
(\mathbf{m g} / \mathbf{d L})\end{array}$ & RF & ANA & Clinical manifestation & Biopsy/lgG4/IgG ratio \\
\hline 1 & 73 & 2890 & $<6$ & 40 & $\begin{array}{l}\text { Lymph, Mikulicz's disease } \\
\text { Prostatitis }\end{array}$ & Prostate/0.60 \\
2 & 76 & 2210 & $<6$ & 40 & Mikulicz's, RPF & Submandibular gland/0.40 \\
3 & 79 & 1460 & $<6$ & 160 & IN, IP, Küttner's tumor, Lymph, RPF & Submandibular gland/0.73 \\
& & & & & \\
4 & 66 & 1090 & 30.3 & 40 & AlP, IN, Renal pseudotumor & Kidney/0.70 \\
5 & 73 & 592 & $<6$ & 320 & IN, IP, Lymph, RPF, Sialadenitis & Submandibular gland/0.43 \\
6 & 62 & 736 & 52.0 & $<40$ & Sialadenitis, Lymph & Parotid gland/0.30* \\
7 & 77 & 738 & $<6$ & $<40$ & Mikulicz's disease & ND. \\
8 & 74 & 389 & $<6$ & $<40$ & Retro-orbital tumor & Retro-orbital tumor/0.48 \\
9 & 76 & 760 & $<6$ & 40 & AlP, Periureteritis & Ureter/0.38 \\
10 & 52 & 383 & $<6$ & $<40$ & Küttner's tumor & Submandibular gland/0.57 \\
11 & 70 & 724 & $<6$ & $<40$ & Küttner's tumor, Lymph & Lachrymal gland/0.41 \\
12 & 46 & 675 & 26.8 & 80 & Mikulicz's disease & Lachrymal gland/0.50 \\
13 & 37 & 533 & $<6$ & $<40$ & Mikulicz's disease & ND \\
14 & 77 & 655 & $<6$ & 80 & RPF & Retroperitoneal/0.70 \\
15 & 76 & 458 & $<6$ & $<40$ & AIP, RPF & Pancreas/0.43 \\
16 & 62 & 315 & $<6$ & 40 & AIP, RPF & ND \\
17 & 79 & 309 & ND & $<40$ & RPF & Orbital tumor/0.59 \\
18 & 79 & 1960 & 65 & 40 & Orbital tumor, Lymph, Lung nodule & (SS-A)
\end{tabular}

AIP, autoimmune pancreatitis; ANA, antinuclear antibody; IN, interstitial nephritis; IP, interstitial pneumonia; Lymph, lymphadenopathy; ND, not determined; RF, rheumatoid factor; RPF, retroperitoneal fibrosis; SS-A, anti-SS-A antibody; *, lgG4-positive plasmacytes $>100 /$ high-power fields.

IgG4-RD on the basis of hyper-IgG4 $\gamma$-globulinemia and typical clinical findings after other diseases were ruled out. Test results of four patients (cases 4, 6, 12, and 18) were positive for rheumatoid factor (RF), those of 10 patients (cases 1 to $5,9,12,14,16$, and 18) were positive for antinuclear antibody (ANA), and those of two patients (cases 3 and 16) were positive for anti-SS-A antibody. Retroperitoneal fibrosis (RPF) was the most frequent clinical manifestation in our cohort.

\section{Increased serum BAFF and APRIL in IgG4-RD}

As shown in Figure 1a, serum levels of BAFF in patients with IgG4-RD before GC therapy ( $n=13,1.512 \pm 0.393$ $\mathrm{ng} / \mathrm{mL}$ ) were significantly higher than those in healthy controls $(n=10,0.904 \pm 0.262 \mathrm{ng} / \mathrm{mL})(P<0.01)$, and there were no significant differences in the serum levels of BAFF between patients with IgG4-RD before GC therapy and patients with pSS $(n=13,1.820 \pm 0.954$ $\mathrm{ng} / \mathrm{mL})(P=0.383)$. Serum levels of BAFF in patients with IgG4-RD after GC therapy $(n=5,0.749 \pm 0.283$ $\mathrm{ng} / \mathrm{mL}$ ) were lower than in those before GC therapy ( $P$ $<0.01$ ). In contrast, as shown in Figure 1b, serum levels of APRIL in patients with IgG4-RD before GC therapy $(n=13,3.736 \pm 3.271 \mathrm{ng} / \mathrm{mL})$ were significantly higher than those in the healthy controls $(n=10,1.327 \pm$ $1.259 \mathrm{ng} / \mathrm{mL})(P<0.01)$, however, unlike BAFF, the levels were significantly lower than those in patients with $\mathrm{pSS}(n=13,11.250 \pm 7.418 \mathrm{ng} / \mathrm{mL})(P<0.01)$.

Inverse correlation between serum APRIL and IgG4 in patients with IgG4-RD

While no significant correlation was found between serum levels of BAFF and IgG4 in patients with IgG4RD before GC therapy ( $n=13, r=-0.159, P=0.603$ ) (Figure 2a), a significant inverse correlation was found for APRIL before GC therapy $(n=13, r=-0.626, P=$ 0.022) (Figure $2 \mathrm{~b}$ ).

\section{No correlation between number of affected organs and} serum BAFF or APRIL in patients with IgG4-RD

To assess the association between serum BAFF/APRIL and disease severity, we counted the number of affected organs from a list of 10 organs (lacrimal glands, salivary glands, lung, pancreas, kidney, retroperitoneum, lymph node, thyroid glands, prostate, and orbit), which are known to be involved in IgG4-RD. As shown in Figure $3 \mathrm{a}$, a significant correlation between the number of affected organs and serum levels of IgG4 was found in patients with IgG4-RD ( $n=18, r=0.638, P=0.004)$. However, as shown in Figure $3 \mathrm{~b}$ and $3 \mathrm{c}$, no significant correlation was found between the number of affected organs and serum levels of BAFF $(n=13, r=-0.307, P$ 

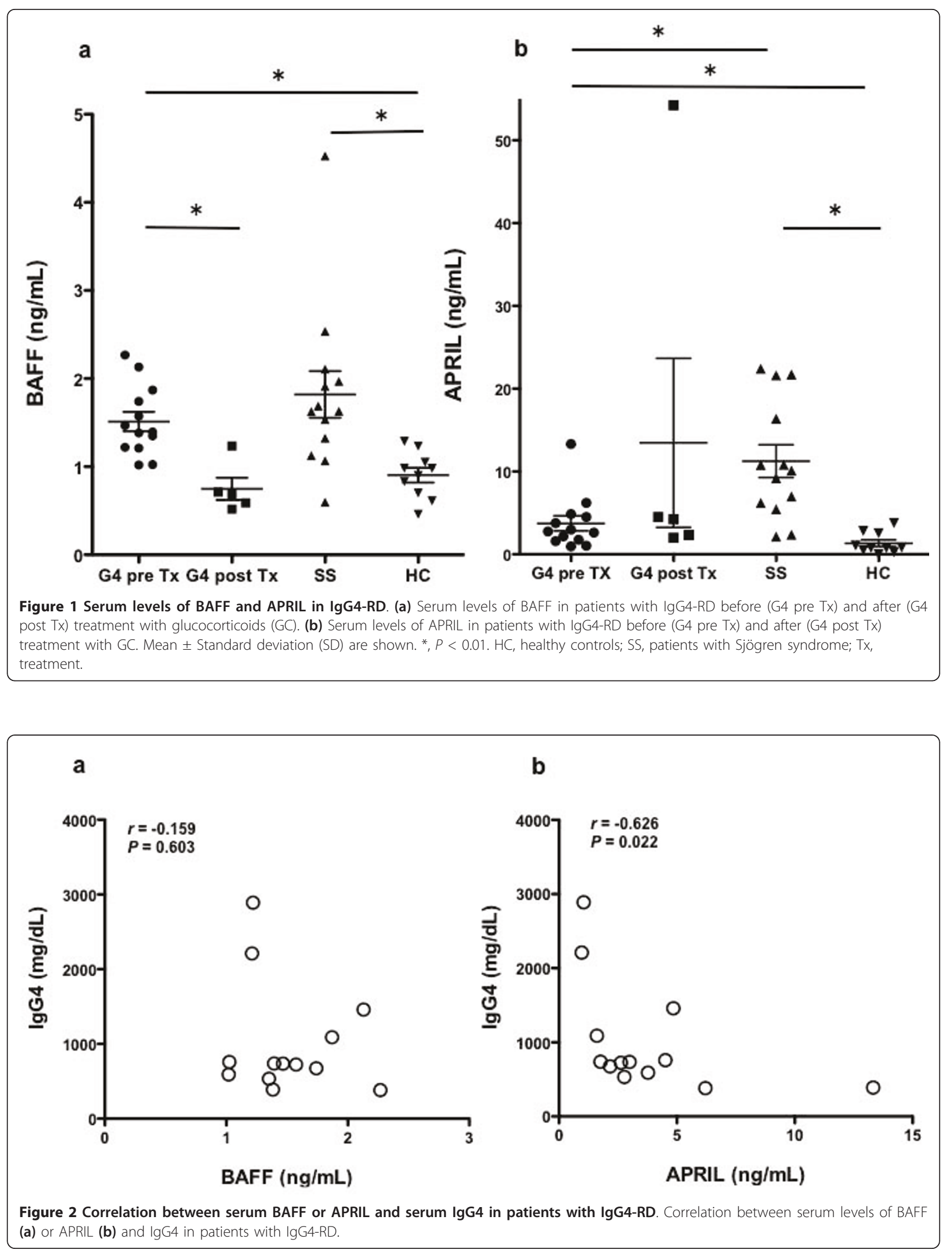


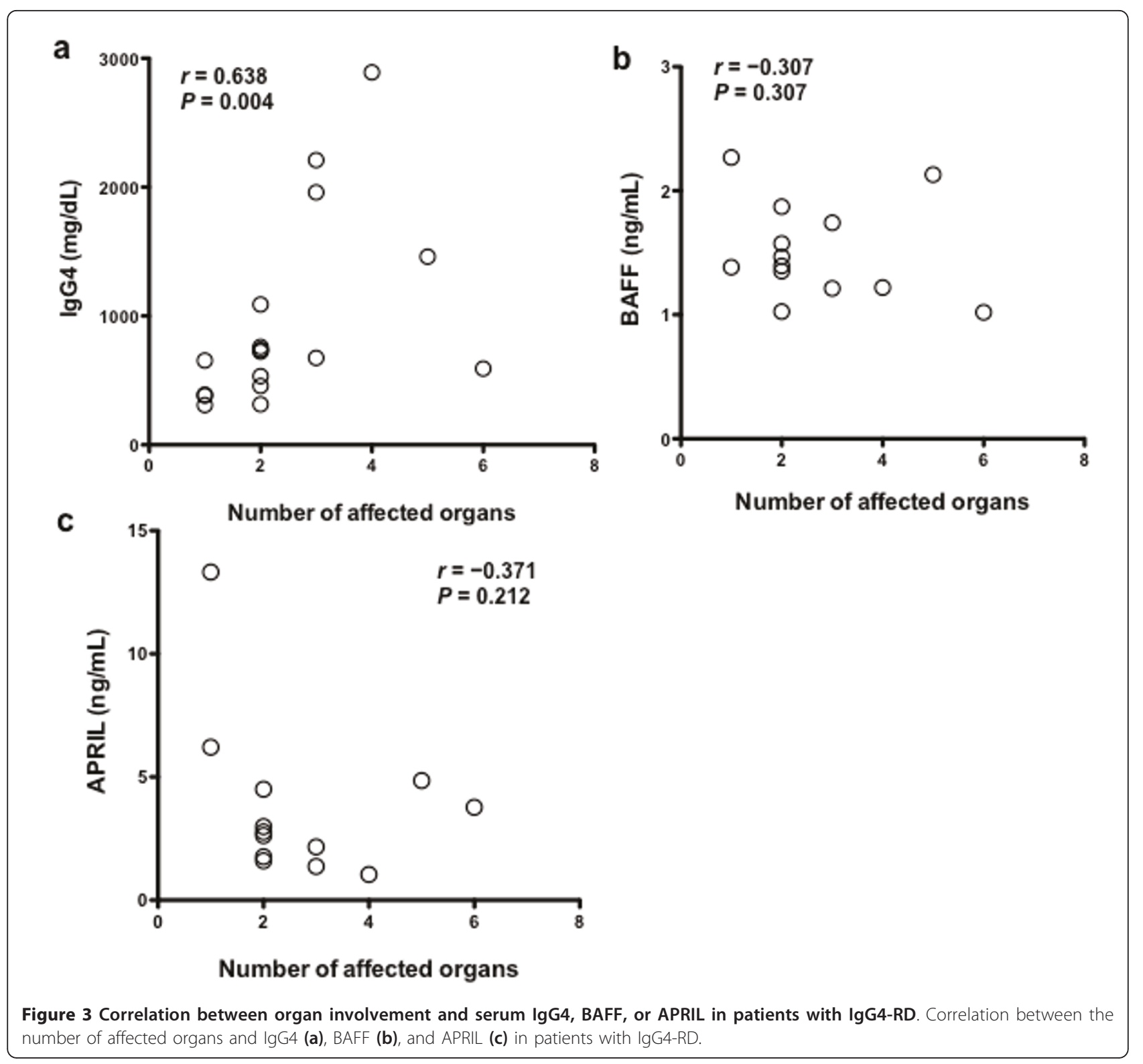

$=0.307)$ or APRIL $(n=13, r=-0.371, P=0.212)$ in patients with IgG4-RD before GC therapy.

\section{Changes in serum BAFF and APRIL in patients with IgG4- $\mathrm{RD}$ during $\mathrm{GC}$ therapy}

Six patients with IgG4-RD were treated with oral prednisolone $(0.6 \mathrm{mg} / \mathrm{kg} /$ day $)$ for two weeks, tapering thereafter by $10 \%$ of the dose every two weeks, and serum samples were drawn repeatedly to monitor serum BAFF and APRIL during treatment (Figure 4). After treatment, serum levels of BAFF dramatically declined to levels observed in healthy controls in most cases; however, the levels increased again during follow-up (Figure 4a). In contrast, serum levels of APRIL did not decrease during treatment and increased markedly after treatment in most cases (Figure 4b).

\section{Discussion}

This is the first study to demonstrate both an increase in BAFF and APRIL levels in patients with IgG4-RD as well as the differential effects of GC treatment on BAFF and APRIL in patients with IgG4-RD. Promotion of B cell activation, plasmacyte differentiation, and germinal center formation by BAFF and APRIL [42], and ectopic germinal center formation in lacrimal and salivary glands from patients with MD [43] suggest that inappropriate BAFF and APRIL may contribute to progressive plasmacyte infiltration and ectopic germinal center 


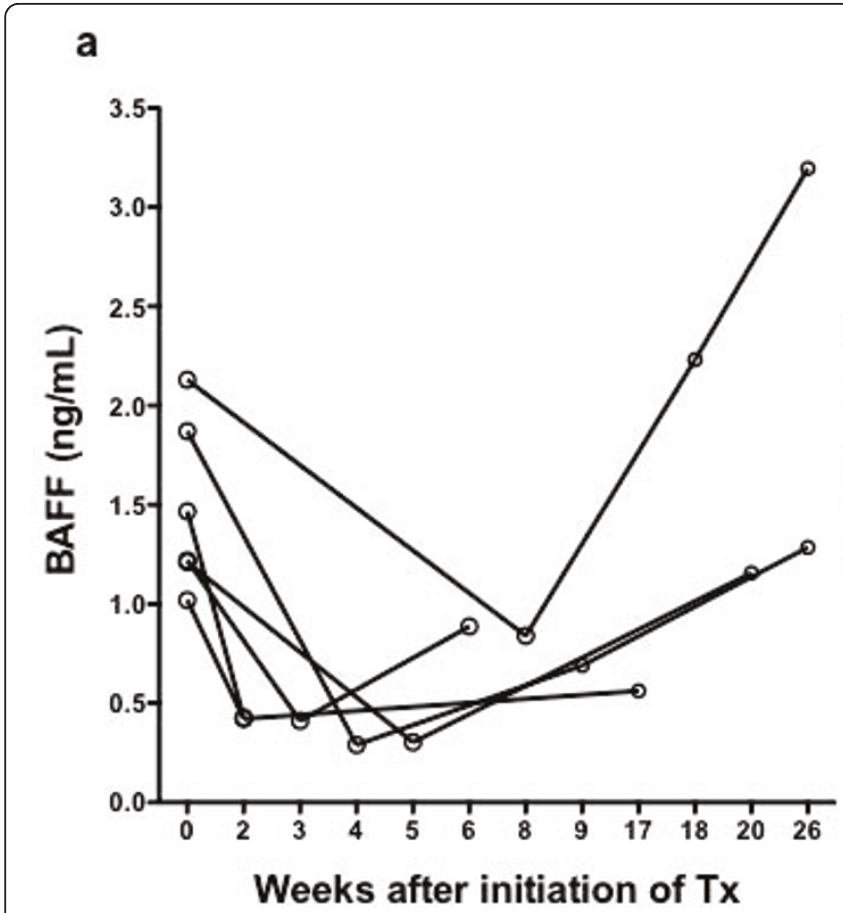

\section{b}

Figure 4 Changes in serum levels of BAFF and APRIL in patients with IgG4-RD during GC therapy. Serum levels of BAFF (a) and APRIL (b) were monitored during and after GC therapy $(n=6)$.

formation in the target organs of patients with IgG4RD. In addition, it has been demonstrated that BAFF and APRIL enhance class switching to produce IgG4 and IgE in the presence of IL-4 $[44,45]$. Previous studies have shown that production of Th2 cytokines, such as IL-4, IL-5, and IL-13 was augmented in the tissue of patients with AIP [20]. Therefore, increased expression of both cytokines may contribute to the pathogenesis of IgG4-RD in concert with cognate Th2 cells. In particular, three (cases 3,4 and 12) out of five patients (cases 3, 4, 10, 11 and 12) with high BAFF levels (>1.5 $\mathrm{ng} / \mathrm{mL}$ ) had positive test results for autoantibodies (for example, RF or anti-SS-A antibody), which is consistent with previous studies showing that serum BAFF levels were correlated with positive results for serum autoantibodies in patients with RA [29], SLE [30], pSS [31], or IM [33]. BAFF might also play a role in the breakdown of B cell tolerance in patients with IgG4-RD. Recently, it has been reported that serum levels of BAFF were higher in patients with AIP than in those with pancreatic cancer or chronic pancreatitis [46]. The same studies also demonstrated that serum BAFF levels were significantly correlated with serum levels of IgG and IgG4 in patients with AIP, which was not observed in our cohort. The relatively small number of patients in our study or the enrollment of different subsets of patients might explain this discrepancy.
Of interest, we found an inverse correlation between serum APRIL and serum IgG4 levels in patients with IgG4-RD. In SLE, a similar inverse correlation between serum APRIL levels and anti-double-stranded DNA antibody titers has been reported [47], and serum APRIL was inversely associated with disease activity. Thus, APRIL might serve as a protective factor against the progression of IgG4-RD. In our cohort, serum IgG4 levels were significantly correlated with the number of affected organs, clearly indicating that serum IgG4 levels reflect disease severity. Although no significant correlation existed between serum BAFF levels and serum immunoglobulins or the number of affected organs, GC treatment dramatically reduced serum levels of BAFF as well as serum IgG4. In patients with AIP, reduced serum levels of BAFF after 12 weeks of GC treatment have been reported [46], a result similar to our finding. Thus, serum BAFF levels might reflect the clinical activity of this disease. During long-term (up to 26 weeks) follow-up, we observed that the elevated levels of serum BAFF reoccurred in most cases; however, no patients suffered clinical relapse. Further follow-up study will be needed to clarify the relationship between the reoccurrence of elevated serum BAFF and clinical relapse in IgG4-RD. In contrast to the rapid reduction of BAFF by GC treatment, serum levels of APRIL increased over the course of treatment. Similar changes in serum levels of BAFF and APRIL have been reported in patients with 
GC-treated SLE [47]. Furthermore, no significant correlation was observed between serum BAFF levels and serum APRIL during GC treatment in our patients (data not shown). Thus, universal but distinct mechanisms might exist to control the expression of BAFF and APRIL during GC treatment.

\section{Conclusions}

We demonstrate for the first time that serum BAFF and APRIL levels are increased in patients with IgG4-RD and that the levels of both are indirectly related to clinical activity. Our findings add to the body of knowledge on the role of BAFF and APRIL in the pathogenesis of IgG4-RD. Further longitudinal studies with larger numbers of patients are required to determine the role of the BAFF/APRIL system and to determine whether BAFF and APRIL might serve as therapeutic targets in IgG4-RD.

\begin{abstract}
Abbreviations
AIP: autoimmune pancreatitis; ANA: anti-nuclear antibody; APRIL: a proliferation-inducing ligand; BAFF: B cell-activating factor of the tumor necrosis factor family; BCMA: B cell maturation antigen; BLys: B-lymphocyte stimulator; CA II: carbonic anhydrase II; ELISA: enzyme-linked immunosorbent assay; GC: glucocorticoid; Ig: immunoglobulin; IgG4-RD: immunoglobulin G4related disease; IL: interleukin; IM: inflammatory myopathy; MD: Mikulicz's disease; PSTI: pancreatic secretory trypsin inhibitor; pSS: primary Sjögren's syndrome; RA: rheumatoid arthritis; RF: rheumatoid factor; RPF: retroperitoneal fibrosis; SD: standard deviation; SLE: systemic lupus erythematosus; SSc: systemic sclerosis; TACl: transmembrane activator and calcium-modulating cyclophilin ligand interactor; TALL-1: TNF and apoptosis leukocyte-expressed ligand-1; Th 2: T helper 2; TNF: tumor necrosis factor; TRDL-1: TNF-related death ligand 1.
\end{abstract}

\section{Acknowledgements}

This work was supported by Health and Labour Sciences Research Grants for the Study of Intractable Diseases from the Ministry of Health, Labour and Welfare, Japan

\section{Authors' contributions}

KK and DK were responsible for the study design, acquisition, analysis and interpretation of data, and manuscript preparation. YH, KK, NY, HY, KO, TF, and TM participated in enrollment of patients and assisted in interpretation of data. All authors have read and approved the manuscript for publication.

\section{Competing interests}

The authors declare that they have no competing interests.

Received: 3 November 2011 Revised: 29 March 2012

Accepted: 24 April 2012 Published: 24 April 2012

\section{References}

1. Masaki Y, Kurose N, Umehara H: IgG4-related disease: a novel lymphoproliferative disorder discovered and established in Japan in the 21st century. J Clin Exp Hematop 2011, 51:13-20.

2. Masaki Y, Dong L, Kurose N, Kitagawa K, Morikawa Y, Yamamoto M, Takahashi H, Shinomura Y, Imai K, Saeki T, Azumi A, Nakada S, Sugiyama E, Matsui S, Origuchi T, Nishiyama S, Nishimori I, Nojima T, Yamada K, Kawano M, Zen Y, Kaneko M, Miyazaki K, Tsubota K, Eguchi K, Tomoda K, Sawaki T, Kawanami T, Tanaka M, Fukushima T, Sugai S, Umehara H: Proposal for a new clinical entity, lgG4-positive multiorgan lymphoproliferative syndrome: analysis of 64 cases of lgG4-related disorders. Ann Rheum Dis 2009, 68:1310-1315.
3. Okazaki K, Uchida K, Miyoshi H, Ikeura T, Takaoka M, Nishio A: Recent concepts of autoimmune pancreatitis and IgG4-related disease. Clin Rev Allergy Immunol 2011, 41:126-138.

4. Umehara H, Okazaki K, Masaki Y, Kawano M, Yamamoto M, Saeki T, Matsui S, Sumida T, Mimori T, Tanaka Y, Tsubota K, Yoshino T, Kawa S, Suzuki R, Takegami T, Tomosugi N, Kurose N, Ishigaki Y, Azumi A, Kojima M, Nakamura S, Inoue D: A novel clinical entity, IgG4-related disease (lgG4RD): general concept and details. Mod Rheumatol 2011, 22:1-14.

5. Deshpande V, Chicano S, Finkelberg D, Selig MK, Mino-Kenudson M, Brugge WR, Colvin RB, Lauwers GY: Autoimmune pancreatitis: a systemic immune complex mediated disease. Am J Surg Pathol 2006, 30:1537-1545.

6. Otsuki M, Chung JB, Okazaki K, Kim MH, Kamisawa T, Kawa S, Park SW, Shimosegawa T, Lee K, Ito T, Nishimori I, Notohara K, Naruse S, Ko SB, Kihara Y: Asian diagnostic criteria for autoimmune pancreatitis: consensus of the Japan-Korea Symposium on Autoimmune Pancreatitis. J Gastroenterol 2008, 43:403-408.

7. Chari ST, Smyrk TC, Levy MJ, Topazian MD, Takahashi N, Zhang L, Clain JE, Pearson RK, Petersen BT, Vege SS, Farnell MB: Diagnosis of autoimmune pancreatitis: the Mayo Clinic experience. Clin Gastroenterol Hepatol 2006, 4:1010-1016; quiz 1934.

8. Takuma K, Kamisawa T, Igarashi Y: Autoimmune pancreatitis and IgG4related sclerosing cholangitis. Curr Opin Rheum 2011, 23:80-87.

9. Kitagawa S, Zen Y, Harada K, Sasaki M, Sato Y, Minato H, Watanabe K, Kurumaya H, Katayanagi K, Masuda S, Niwa H, Tsuneyama K, Saito K, Haratake J, Takagawa K, Nakanuma Y: Abundant IgG4-positive plasma cell infiltration characterizes chronic sclerosing sialadenitis (Kuttner's tumor). Am J Surg Pathol 2005, 29:783-791.

10. Dahlgren M, Khosroshahi A, Nielsen GP, Deshpande V, Stone JH: Riedel's thyroiditis and multifocal fibrosclerosis are part of the lgG4-related systemic disease spectrum. Arthritis Care Res 2010, 62:1312-1318.

11. Stone $J H$, Khosroshahi A, Hilgenberg A, Spooner A, Isselbacher EM, Stone JR: IgG4-related systemic disease and lymphoplasmacytic aortitis. Arthritis Rheum 2009, 60:3139-3145.

12. Saeki T, Nishi S, Imai N, Ito T, Yamazaki H, Kawano M, Yamamoto M, Takahashi H, Matsui S, Nakada S, Origuchi T, Hirabayashi A, Homma N, Tsubata Y, Takata T, Wada Y, Saito A, Fukase S, Ishioka K, Miyazaki K, Masaki Y, Umehara H, Sugai S, Narita I: Clinicopathological characteristics of patients with IgG4-related tubulointerstitial nephritis. Kidney Int 2010, 78:1016-1023.

13. Stone JR: Aortitis, periaortitis, and retroperitoneal fibrosis, as manifestations of IgG4-related systemic disease. Curr Opin Rheumatol 2011, 23:88-94.

14. Hamano H, Kawa S, Ochi Y, Unno H, Shiba N, Wajiki M, Nakazawa K, Shimojo H, Kiyosawa K: Hydronephrosis associated with retroperitoneal fibrosis and sclerosing pancreatitis. Lancet 2002, 359:1403-1404.

15. Okazaki K, Uchida K, Ohana M, Nakase H, Uose S, Inai M, Matsushima Y, Katamura K, Ohmori K, Chiba T: Autoimmune-related pancreatitis is associated with autoantibodies and a Th1/Th2-type cellular immune response. Gastroenterology 2000, 118:573-581.

16. Nishi H, Tojo A, Onozato ML, Jimbo R, Nangaku M, Uozaki H, Hirano K, Isayama H, Omata M, Kaname S, Fujita T: Anti-carbonic anhydrase II antibody in autoimmune pancreatitis and tubulointerstitial nephritis. Nephrol Dial Transplant 2007, 22:1273-1275.

17. Endo T, Takizawa S, Tanaka S, Takahashi M, Fujii H, Kamisawa T, Kobayashi T: Amylase alpha-2A autoantibodies: novel marker of autoimmune pancreatitis and fulminant type 1 diabetes. Diabetes 2009, 58:732-737.

18. Asada M, Nishio A, Uchida K, Kido M, Ueno S, Uza N, Kiriya K, Inoue S, Kitamura H, Ohashi S, Tamaki H, Fukui T, Matsuura M, Kawasaki K, Nishi T, Watanabe N, Nakase H, Chiba T, Okazaki K: Identification of a novel autoantibody against pancreatic secretory trypsin inhibitor in patients with autoimmune pancreatitis. Pancreas 2006, 33:20-26.

19. Frulloni L, Lunardi C, Simone R, Dolcino M, Scattolini C, Falconi M, Benini L, Vantini I, Corrocher R, Puccetti A: Identification of a novel antibody associated with autoimmune pancreatitis. N Eng J Med 2009, 361:2135-2142

20. Zen Y, Fujii T, Harada K, Kawano M, Yamada K, Takahira M, Nakanuma Y: Th2 and regulatory immune reactions are increased in immunoglobin G4-related sclerosing pancreatitis and cholangitis. Hepatology 2007, 45:1538-1546.

21. Zen Y, Nakanuma Y: Pathogenesis of IgG4-related disease. Curr Opin Rheumatol 2011, 23:114-118. 
22. Mackay F, Schneider P, Rennert P, Browning J: BAFF AND APRIL: a tutoria on B cell survival. Ann Rev Immunol 2003, 21:231-264.

23. Tangye SG, Bryant VL, Cuss AK, Good KL: BAFF, APRIL and human B cell disorders. Semin Immunol 2006, 18:305-317.

24. Lopez-Fraga M, Fernandez R, Albar JP, Hahne M: Biologically active APRIL is secreted following intracellular processing in the Golgi apparatus by furin convertase. EMBO Rep 2001, 2:945-951.

25. Liu Z, Davidson A: BAFF and selection of autoreactive B cells. Trends Immunol 2011, 32:388-394.

26. Mackay F, Tangye SG: The role of the BAFF/APRIL system in B cell homeostasis and lymphoid cancers. Curr Opin Pharmacol 2004, 4:347-354.

27. Mackay F, Schneider P: Cracking the BAFF code. Nat Rev Immunol 2009, 9:491-502.

28. Mackay F, Woodcock SA, Lawton P, Ambrose C, Baetscher M, Schneider P, Tschopp J, Browning JL: Mice transgenic for BAFF develop lymphocytic disorders along with autoimmune manifestations. J Exp Med 1999, 190:1697-1710.

29. Bosello S, Youinou P, Daridon C, Tolusso B, Bendaoud B, Pietrapertosa D, Morelli A, Ferraccioli G: Concentrations of BAFF correlate with autoantibody levels, clinical disease activity, and response to treatment in early rheumatoid arthritis. J Rheumatol 2008, 35:1256-1264.

30. Stohl W, Metyas S, Tan SM, Cheema GS, Oamar B, Xu D, Roschke V, Wu Y, Baker KP, Hilbert DM: B lymphocyte stimulator overexpression in patients with systemic lupus erythematosus: longitudinal observations. Arthritis Rheum 2003, 48:3475-3486.

31. Mariette X, Roux S, Zhang J, Bengoufa D, Lavie F, Zhou T, Kimberly R: The level of BLyS (BAFF) correlates with the titre of autoantibodies in human Sjogren's syndrome. Ann Rheum Dis 2003, 62:168-171.

32. Jonsson MV, Szodoray P, Jellestad S, Jonsson R, Skarstein K: Association between circulating levels of the novel TNF family members APRIL and BAFF and lymphoid organization in primary Sjogren's syndrome. J Clin Immunol 2005, 25:189-201.

33. Krystufkova O, Vallerskog T, Helmers SB, Mann H, Putova I, Belacek J, Malmstrom V, Trollmo C, Vencovsky J, Lundberg IE: Increased serum levels of $B$ cell-activating factor (BAFF) in subsets of patients with idiopathic inflammatory myopathies. Ann Rheum Dis 2009, 68:836-843.

34. Matsushita T, Hasegawa M, Yanaba K, Kodera M, Takehara K, Sato S: Elevated serum BAFF levels in patients with systemic sclerosis: enhanced BAFF signaling in systemic sclerosis B lymphocytes. Arthritis Rheum 2006, 54:192-201.

35. Kang JS, Yoon YD, Ahn JH, Kim SC, Kim KH, Kim HM, Moon EY: B cellactivating factor is a novel diagnosis parameter for asthma. Int Arch Allergy Immunol 2006, 141:181-188,

36. Jee HM, Kim KW, Hong JY, Sohn MH, Kim KE: Increased serum B cellactivating factor level in children with atopic dermatitis. Clin Exp Dermatol 2010, 35:593-598.

37. Stein JV, Lopez-Fraga M, Elustondo FA, Carvalho-Pinto CE, Rodriguez D, Gomez-Caro R, De Jong J, Martinez AC, Medema JP, Hahne M: APRIL modulates B and T cell immunity. J Clin Invest 2002, 109:1587-1598.

38. Varfolomeev E, Kischkel F, Martin F, Seshasayee D, Wang H, Lawrence D, Olsson C, Tom L, Erickson S, French D, Schow P, Grewal IS, Ashkenazi A: APRIL-deficient mice have normal immune system development. Mol Cell Biol 2004, 24:997-1006.

39. Castigli E, Scott S, Dedeoglu F, Bryce P, Jabara H, Bhan AK, Mizoguchi E, Geha RS: Impaired IgA class switching in APRIL-deficient mice. Proc Natl Acad Sci USA 2004, 101:3903-3908.

40. Koyama T, Tsukamoto H, Miyagi Y, Himeji D, Otsuka J, Miyagawa H, Harada M, Horiuchi T: Raised serum APRIL levels in patients with systemic lupus erythematosus. Ann Rheum Dis 2005, 64:1065-1067.

41. Thangarajh M, Masterman T, Rot U, Duvefelt K, Brynedal B, Karrenbauer VD, Hillert J: Increased levels of APRIL (a proliferation-inducing ligand) mRNA in multiple sclerosis. J Neuroimmunol 2005, 167:210-214.

42. Szodoray $\mathrm{P}$, Jonsson R: The BAFF/APRIL system in systemic autoimmune diseases with a special emphasis on Sjogren's syndrome. Scand J Immunol 2005, 62:421-428.

43. Yamada K, Kawano M, Inoue R, Hamano R, Kakuchi Y, Fujii H, Matsumura M, Zen Y, Takahira M, Yachie A, Yamagishi M: Clonal relationship between infiltrating immunoglobulin G4 (IgG4)-positive plasma cells in lacrimal glands and circulating lgG4-positive lymphocytes in Mikulicz's disease. Clin Exp Immunol 2008, 152:432-439.
44. Yamada T, Zhang K, Yamada A, Zhu D, Saxon A: B lymphocyte stimulator activates p38 mitogen-activated protein kinase in human Ig class switch recombination. Am J Respir Cell Mol Biol 2005, 32:388-394.

45. Litinskiy MB, Nardelli B, Hilbert DM, He B, Schaffer A, Casali P, Cerutti A: DCs induce CD40-independent immunoglobulin class switching through BLyS and APRIL. Nat Immunol 2002, 3:822-829.

46. Yamanishi H, Kumagi T, Yokota T, Azemoto N, Koizumi M, Kobayashi Y, Abe M, Murakami H, Hiasa Y, Matsuura B, Kawamoto H, Yamamoto K, Onji M: Clinical significance of B cell-activating factor in autoimmune pancreatitis. Pancreas 2011, 40:840-845.

47. Stohl W, Metyas S, Tan SM, Cheema GS, Oamar B, Roschke V, Wu Y, Baker KP, Hilbert DM: Inverse association between circulating APRIL levels and serological and clinical disease activity in patients with systemic lupus erythematosus. Ann Rheum Dis 2004, 63:1096-1103.

\section{doi:10.1186/ar3810}

Cite this article as: Kiyama et al: Serum BAFF and APRIL levels in patients with IgG4-related disease and their clinical significance. Arthritis Research \& Therapy 2012 14:R86.

\section{Submit your next manuscript to BioMed Central and take full advantage of:}

- Convenient online submission

- Thorough peer review

- No space constraints or color figure charges

- Immediate publication on acceptance

- Inclusion in PubMed, CAS, Scopus and Google Scholar

- Research which is freely available for redistribution

Submit your manuscript at www.biomedcentral.com/submit
Ciomed Central 